\title{
Mistakes in Suffixes in the Written Expression of Kyrgyz Students Who Studied Turkish
}

\author{
Sibel Barcin \\ Lect., Kyrgyz-Turkish Manas University, \\ Kyrgyz Republic \\ E mail: sibel.barcin@manas.edu.kg
}

\begin{abstract}
In this study, Kyrgyz students who studied under the umbrella of Kyrgyz-Turkish Manas University, School of Foreign Languages were evaluated according to the wrong analysis approach in terms of mistakes in suffixes in the Turkish written expression skills. For this purpose, the written expression papers of the 4th midterm exams of twenty eight Kyrgyz students at the B2 level who were studied in the spring semester of the 2018-2019 academic year of Kyrgyz-Turkish Manas University were examined and the data decisively presented. A conclusion was reached in the light of the emerging findings. As a result of the study, it was observed that the students made more mistakes in the suffixes which make more nouns, completions and verbs.
\end{abstract}

Key words: Teaching Turkish, writing skills, written expression, mistakes in suffixes, intermediate level.

DOI: $10.7176 / \mathrm{JSTR} / 5-12-05$

\section{Türkçe Öğrenimi Gören Kırgız Öğrencilerin Yazılı Anlatımlarındaki Ek Yanlışları}

\begin{abstract}
Özet
$\mathrm{Bu}$ çalışmada, Kırgızistan-Türkiye Manas Üniversitesi Yabancı Diller Yüksekokulu çatısı altında öğrenim gören Kırgız öğrencilerin Türkiye Türkçesi yazılı anlatım becerileri ek yanlışları bakımından yanlış çözümlemesi yaklaşımına göre değerlendirilmiştir. Bu amaçla Kırgızistan-Türkiye Manas Üniversitesi 2018-2019 öğretim yılı bahar döneminde öğrenim gören B2 seviyesindeki Kırgız yirmi sekiz öğrencinin Türkiye Türkçesi IV. ara sınavının yazılı anlatım kâğıtları incelenmiş ve veriler tablo hâlinde gösterilmiştir. Ortaya çıkan bulgular ışığında bir sonuca varılmıştır. Araştırmanın sonucunda öğrencilerin daha çok hâl ve fiilden isim yapan eklerde hata yaptıkları gözlenmiştir.
\end{abstract}

Anahtar kelimeler: Türkçe öğretimi, yazma becerisi, yazılı anlatım, ek yanlışları, orta düzey.

\section{Giriș}

Yazma becerisi ikinci bir dilin öğrenilmesinde en zor kazanılan beceridir. Öğrenci yazma becerisinde alfabe, kelime, cümle, paragraf ve metin öğrenimi aşamalarından geçer. Nasıl ki hayatında hiç spor yapmamış biri maraton koşamazsa bir öğrenciden de temel düzeyde metin yazması beklenemez.

Çakır'ın (2010, s. 166) ifade ettiği gibi dil öğretiminde dört temel beceriden birisi olan yazma becerisi öğrencilerin ve öğretmenlerin en zorlandığı beceridir. Öğrencilerden neyi ne kadar öğrenebildiklerini görebilmek ve bu süreci değerlendirebilmek için dört temel beceriden ikisi olan konuşma ve yazma becerilerinin kullanılması istenir. Bu iki beceri arasında öğrenciler en çok yazma becerisinde zorlanırlar. Diğer dil becerileri ile arasında güçlü bir ilişki bulunan yazma becerisi ancak diğer dil becerilerinin kazanılması durumunda olumlu yönde gelişecektir. Çünkü okuyan, dinleyen ve konuşan bireylerin bu etkinlikler sayesinde ufukları açılacak, hayal dünyaları gelişecek ve bu sayede yazma konusunda sıkıntı yaşamayacaklardır. Bu nitelik, yazma eyleminin bir anda ve kısa sürede gerçekleştirilebilecek bir iş olmadığını göstermektedir (Maden, Dinçel ve Maden, 2015, s. 764).

\section{Yanlış Çözümlemesi}

Çerçi, Derman ve Bardakçı'nın (2016, s. 696) belirttiği gibi Türkçe öğretiminde öğrencilerin yanlışlarının yanlış ya da hata olarak adlandırılabilmesi için kullanılan iki önemli yaklaşım vardır. Bu yaklaşımlar karşıtsal çözümleme ve yanlış çözümlemesidir.

51 | $P$ a g e

www.iiste.org 
Yanlış çözümlemesi, öğrencilerin yaptıkları yanlışların gözlenmesi ve belli bir sisteme göre sinıflandırılıp analiz edilmesidir. Yanlış çözümlemesi, öğretmenin öğretim tekniğini ve öğretim materyallerini gözden geçirmesi, öğretme sürecini değerlendirmesi ve öğretim programının yeniden düzenlenmesi konusunda yol göstericidir (Bölükbaş, 2011, s. 1359).

Yanlış çözümlemeleri öğrencilerin dil öğrenim sürecinde yaptıkları yaygın yanlışları sistematik biçimde tanımlayarak öğretmene, ders kitabı yazarlarına yol gösterir. Bunun yanında, öğrencilerin öğrendikleri dile ilişkin varsayım ve genellemelerinin doğru olup olmadığı konusunda da onlara geribildirim sağlar. Yabancı dil olarak Türkçe öğreniminde öğrencilerin yaptıkları yanlışları tanımlamayı amaçlayan çalışmaların genel olarak bu yanlışları tek yönüyle tanımladıkları görülmektedir (Çetinkaya, 2015, s. 167).

Hata analizi olarak da ifade edilen yanlış çözümlemesi öğretmenlere, öğrencilerin yapmış oldukları hataların kaynaklarını bulmak ve onlara karşı pedagojik önlemler almak için yardımcı olur (Şahin, 2013, s. 434).

Büyükikiz’e göre (2013, s. 53) karşıtsal çözümleme, dil öğreniminde karşılaşılan güçlükleri, ana dili girişimine ve aktarmaya dayandırır. Yanlış çözümlemesi ise çözümlemesini öğrencilerden aldığı verilere dayandırır. Böylelikle karşıtsal çözümleme, ana dili ile hedef dili karşılaştırarak öğrencinin hedef dili öğrenmesi sırasında karşılaşabileceği güçlüklere ilişkin kestirimlerde bulunurken yanlış çözümlemesi, öğrencilerden elde ettiği verilere dayanarak güçlükleri belirler.

\section{Yöntem}

$\mathrm{Bu}$ çalışmada Kırgızistan-Türkiye Manas Üniversitesi Yabancı Diller Yüksekokulu çatısı altında öğrenim gören Türk soylu yirmi sekiz öğrencinin yazılı anlatım kâğıdı yanlış çözümlemesi yaklaşımına göre değerlendirilmiştir. Bu çalışmada nitel araştırma yöntemlerinden içerik analizi kullanılmıştır. "İçerik analizinde temel amaç, toplanan verileri açıklayabilecek kavramlara ve ilişkilere ulaşmaktır. İçerik analizinde temelde yapılan işlem, birbirine benzeyen verileri belirli kavramlar ve temalar çerçevesinde bir araya getirmek ve bunları okuyucunun anlayabileceği bir biçimde düzenleyerek yorumlamaktır." (Şimşek ve Yıldırım, 2011, s. 227)

\section{Sinırlılıklar}

Çalışma, Kırgızistan-Türkiye Manas Üniversitesi Yabancı Diller Yüksekokulu bünyesinde öğrenim gören Türk soylu yirmi sekiz öğrenci ile sınırlıdır.

\section{Çalışma Grubu}

Araştırmanın çalışma grubunu Kırgızistan-Türkiye Manas Üniversitesi 2018-2019 öğretim yılı bahar döneminde öğrenim gören B2 seviyesindeki Türk soylu yirmi sekiz öğrenci oluşturmaktadır.

Tablo 1: Araştırmaya Katılan Öğrencilerin Cinsiyet Dağılımına İlişkin Bilgileri

\begin{tabular}{lc}
\hline Cinsiyet & \\
\hline K1z & 22 \\
Erkek & 6 \\
\hline Toplam & $\mathbf{2 8}$
\end{tabular}

Araştırmaya katılan öğrencilerin cinsiyet dağılımı ile ilgili bilgiler Tablo 1'de verilmiştir. Öğrencilerden yirmi ikisi kız, altısı ise erkektir.

Tablo 2: Araştırmaya Katılan Öğrencilerin Yaş Dağılımına İlişkin Bilgileri

\begin{tabular}{ll}
\hline Yaş & \\
\hline $17-22$ & 27 \\
22 ve üstü & 1 \\
\hline Toplam & $\mathbf{2 8}$
\end{tabular}

Araştırmaya katılan öğrencilerin yaş dağılımına ilişkin bilgiler Tablo 2'de verilmiştir. Yaşları 17-22 olan 27, 22 ve üstü olan 1 öğrenci vardır. 
Tablo 3: Araştırmaya Katılan Öğrencilerin Seçtiği Bölüme İlişkin Bilgileri

\begin{tabular}{|c|c|}
\hline Cinsiyeti & Hangi Bölüm Öğrencisi Olduğu \\
\hline$\overline{\mathrm{K}} 1 \mathrm{Z}$ & Türkoloji \\
\hline Kiz & Türkoloji \\
\hline Erkek & Türkoloji \\
\hline K1Z & Türkoloji \\
\hline $\mathrm{K} 1 \mathrm{z}$ & Türkoloji \\
\hline K1z & Türkoloji \\
\hline $\mathrm{K} 1 \mathrm{z}$ & Türkoloji \\
\hline Kiz & Türkoloji \\
\hline K1z & Türkoloji \\
\hline Kiz & Türkoloji \\
\hline $\mathrm{K} 1 \mathrm{z}$ & Türkoloji \\
\hline Kiz & Türkoloji \\
\hline K1z & Türkoloji \\
\hline Kiz & Türkoloji \\
\hline K1z & Türkoloji \\
\hline Kiz & Türkoloji \\
\hline $\mathrm{K} 1 \mathrm{z}$ & Türkoloji \\
\hline Erkek & Turizm \\
\hline Erkek & Turizm \\
\hline Erkek & Turizm \\
\hline $\mathrm{K} 1 \mathrm{z}$ & Müzik \\
\hline K1z & Müzik \\
\hline $\mathrm{K} 1 \mathrm{z}$ & Müzik \\
\hline K1z & Antrenörlük Eğitimi \\
\hline Kiz & Beden Eğitimi ve Spor Öğretmenliği \\
\hline Erkek & Beden Eğitimi ve Spor Öğretmenliği \\
\hline Erkek & Ekonomi \\
\hline $\mathrm{K} 1 \mathrm{Z}$ & Eğitim Bilimleri \\
\hline
\end{tabular}

Araştırmaya katılan öğrencilerin seçtiği bölüme ilişkin bilgiler Tablo 3'te gösterilmiştir.

Tablo 4: Araştırmaya Katılan Öğrencilerin Öğrenim Düzeyine İlişkin Bilgileri Öğrenim Düzeyi

\begin{tabular}{lc}
\hline Lisans & 27 \\
Yüksek Lisans & 1 \\
\hline Toplam & $\mathbf{2 8}$
\end{tabular}

Araştırmaya katılan öğrencilerin öğrenim düzeyleriyle ilgili bilgiler Tablo 4’te verilmiştir. Öğrencilerden yirmi yedisinin lisans, birinin ise yüksek lisans düzeyinde öğrenim gördüğü anlaşılmaktadır.

\section{Verilerin Toplanması}

Araştırmada Kırgızistan-Türkiye Manas Üniversitesi 2018-2019 öğretim yılı bahar döneminde öğrenim gören Türk soylu yirmi sekiz öğrencinin Türkiye Türkçesi IV. ara sınavında yer alan yazılı anlatım sorularına verdikleri cümleler kullanılmaktadır.

Türkiye Türkçesi IV. ara sınavında bulunan yazılı anlatım sınavı üç konudan oluşur. Öğrencilerden "Çocukluk, gençlik ve yaşlılık gibi dönemler arasında; düşünce, tecrübe, zevk ve yaşayış bakımından ne gibi farklılıklar vardır? 'Gençler bilse, yaşlılar yapabilse...' sözünden yola çıkarak anlatınız.", "Günümüzde hangi çevre sorunlarıyla karşılaşıyoruz? Bu sorunlarla başa çıkabilmek için neler yapmamız ve nelerden uzak durmamız gerekir? 'Yaşadığımız dünya bize geçmiş nesillerin mirası, gelecek nesillerin ise emanetidir.' sözünden ne anlıyorsunuz? Anlatınız." ve "Toplumun yazılı olmayan kuralları nelerdir? Bir birey bu kurallara uymazsa ne gibi sorunlarla karşılaşır? 'Sürüden ayrılanı kurt 
kapar.' atasözünden yola çıkarak insan ve toplum ilişkisini anlatınız.” konularından herhangi biri ile metin yazmaları istenir.

\section{Verilerin Analizi}

Araştırmada yazılı anlatım kâğıtları yanlış çözümlemesi yaklaşımına göre değerlendirilmiştir. Elde edilen veriler tablo hâlinde gösterilmiştir. Bu çalışmada, veriler analiz edilirken Şahin'in (2013, s. 440446) çalışmasından yararlanılmıştır.

\section{Bulgular}

Türkiye Türkçesi 4. ara sınavının yazılı anlatım kâğıtlarında kullanılan cümleler vasıtasıyla aşağıdaki bulgular tespit edilmiştir.

Tablo 5: Araştırmaya Katılan Öğrencilerin Ek Yanlışlarına İlişkin Bulguları

\begin{tabular}{|c|c|}
\hline $\begin{array}{l}\text { Fiilden İsim } \\
\text { Yapım Ekleri }\end{array}$ & $\begin{array}{l}\text { Doğa ve insan ilişkisi ve onunla insanın doğaya veren etkisi günümüzde çok } \\
\text { önemli konu. } \\
\text { Önce gözlerimi kapattım ve düşünen şeyleri canlandırdım. } \\
\text { Bence bilen işi yapmalıyız. } \\
\text { Hayatımız boyunca kurallara uymayan, kendi isteğen şeyleri yapan insanlarla } \\
\text { karşılaşıyoruz. } \\
\text { Ben de günlük hayatta karşılaşmakta olan olaylar hakkında size birazcık bilgi } \\
\text { vereceğim. }\end{array}$ \\
\hline Belirtme Hâli Eki & $\begin{array}{l}\text { Babanın çocuğun düşünmesi ve yardım etmesi lazım. } \\
\text { Anne ve baba çocuğun olduğu gibi kabul etmezler. } \\
\text { Dedem kendi gençliğin anlatırken çok heyecanlanırdı. } \\
\text { İnsanlar kendi yaşamların kolaylaştırmak için olumsuz işler yapıyorlar. } \\
\text { Çöl gibi yerde yaşayan insanlar tabiatın kıymetin daha iyi anlarlar. } \\
\text { Mesela büyüklerimiz halk müziğin seviyor ama küçük kardeşlerimiz onu } \\
\text { sevmiyor. } \\
\text { Yaşlılar hayatının çoğun yaşadığı için tecrübeli, gençler ise onlar gibi tecrübeli } \\
\text { değildir. }\end{array}$ \\
\hline Yönelme Hâli Eki & Boş zamanlarını eğitimge değil de sosyal medyaya ayırıyorlar. \\
\hline Çıkma Hâli Eki & $\begin{array}{l}\text { Ne yazık ki tabiat insanoğlunun olumsuz yaptıklarınan dolayı bozuluyor. } \\
\text { Çevremizdeki insanların hayat hakkındaki düşünceleri birbirinen farklıdır. }\end{array}$ \\
\hline İlgi Hâli Eki & $\begin{array}{l}\text { Modern dünya yüzünden hastalıktın çeşitleri artıyor. } \\
B u \text { için tabiatı koruyalım, ağlatmayalım, kalbini kırmayalım. } \\
\text { Her dönemdin iyi tarafı var. }\end{array}$ \\
\hline Soru Eki & $\begin{array}{l}\text { Biliyormusunuz, hayat gerçekten güzel. } \\
\text { Sonucu nasıl olacak biliyormusunuz? } \\
\text { Hayat çok kısa demi arkadaşlar? }\end{array}$ \\
\hline Kip ve Şahıs Eki & $\begin{array}{l}\text { Dedem zamanında öğretmen olarak çalıştı (çalışmış). } \\
\text { Tabiat da bizim gibi ağlayacak (ağlar), onun da kalbi kırılacak (kırılır). } \\
\text { İnsan doğduğunda önce bebek olacak (olur) sonra çocuk, daha sonra gençlik ve } \\
\text { en sonunda yaşlı olacak (olur). } \\
\text { Ben çocukken "Ne zaman büyüyeceğim?" diye söyleyecektim (söylerdim). } \\
\text { Kuşak çatışması, değişen değerler ve davranışlar sonucunda yaş farkı 5-10 ve } \\
\text { üzerindeki bireyler için gerçekleşmeye başlayacaktır (başlar). }\end{array}$ \\
\hline
\end{tabular}

\section{Yorumlar}

Çalışmaya katılan öğrencilerin yazılı anlatım kâğıtları incelendiğinde fiilden isim yapım eklerinde hata yaptıkları gözlemlenir. Öğrencilerin bu hatayı yapmasının sebebi +DIK ortacının ana dillerinde bulunmamasıdır. Öğrenci "Doğa ve insan ilişkisi ve onunla insanın doğaya veren etkisi günümüzde çok önemli konu.", "Önce gözlerimi kapattım ve düşünen şeyleri canlandırdım.”, "Bence bilen işi yapmalıyız.", "Hayatımız boyunca kurallara uymayan, kendi isteğen şeyleri yapan insanlarla karşılaşıyoruz.", "Ben de günlük hayatta karşılaşmakta olan olaylar hakkında size birazcık bilgi vereceğim." cümlelerinde olumsuz aktarım yaparak +An ortacını kullanmıştır.

Öğrenciler tarafından en fazla hata yapılan konulardan biri belirtme hâli ekidir. Kırgız Türkçesinde belirtme hâli “ $+\mathrm{n} 1,+\mathrm{ni}+\mathrm{nu},+\mathrm{nü},+\mathrm{d}_{1},+\mathrm{di},+\mathrm{du},+\mathrm{dü},+\mathrm{t}$, $+\mathrm{ti},+\mathrm{tu},+$ tü” eklerinden oluşur. Eğer isim soylu

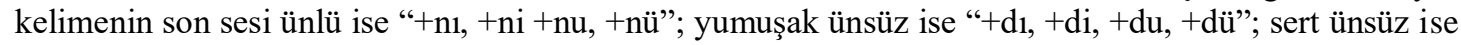


“+tı, +ti, +tu, +tü” eklenir. Özeren'in (2016, s. 747) de belirttiği gibi Kırgız Türkçesi yazı dilinde 3. şahıs iyelik eklerinden sonra belirtme hâli olarak $+n$ biçimi kullanılır. Çalışmaya katılan öğrenciler $+n$ biçiminden sonra belirtme hâlini getirmeyi unutmuşlardır. Yazılı anlatım kâğıtlarındaki belirtme hâli ekiyle ilgili yanlış örnekleri şu şekildedir: "Babanın çocuğun düşünmesi ve yardım etmesi lazım.", "Anne ve baba çocuğun olduğu gibi kabul etmezler.", "Dedem kendi gençliğin anlatırken çok heyecanlanırdı.", "İnsanlar kendi yaşamların kolaylaştırmak için olumsuz işler yapıyorlar." Çöl gibi yerde yaşayan insanlar tabiatın kıymetin daha iyi anlarlar.", "Mesela büyüklerimiz halk müziğin seviyor ama küçük kardeşlerimiz onu sevmiyor.", "Yaşlılar hayatının çoğun yaşadığı için tecrübeli, gençler ise onlar gibi tecrübeli değildir."

Gümüş'e göre (2010, s. 181) Türkiye Türkçesindeki hâl ekleri ile Kırgız Türkçesindeki hâl ekleri arasında işlevsel ve biçimsel benzerliklerin yanı sıra farklılıklar da bulunur.

Çalı̧̧maya katılan öğrencilerin yazılı anlatım kâğıdı incelendiğinde yönelme hâli ekiyle ilgili yanlış örnek bir tane gözlemlenmiştir. Kırgız Türkçesinde yönelme hâlinin " +ga, +ge, +go, +gö +ka, +ke, +ko, +kö” olmak üzere sekiz çeşidi vardır. Eğer isim soylu kelimenin son sesi ünlü ya da yumuşak ünsüz ise “+ga, +ge, +go, +gö”; sert ünsüz ise “+ka, +ke, +ko, +kö” gelir. "Boş zamanlarını eğitimge değil de sosyal medyaya ayırıyorlar." yanlış örneğinde görüldüğü gibi öğrenci olumsuz aktarım yapmıştır.

Özeren'in (2016, s. 756) ifade ettiği gibi Kırgız Türkçesi yazı dilinde ve ağızlarında dudak uyumu dolayısıyla çıkma hâli ekinin düz ve yuvarlak ünlülü biçimleri görülür. Öğrencilerin yazılı anlatım kâğıtlarına "Ne yazık ki tabiat insanoğlunun olumsuz yaptıklarınan dolayı bozuluyor.", "Çevremizdeki insanların hayat hakkındaki düşünceleri birbirinen farklıdır." cümlelerini yazmalarının sebebi de budur. Kırgız Türkçesinde ilgi hâli "+nın, +nin, +nun, +nün, +dın, +din, +dun, +dün, +tın, +tin, +tun, +tün" eklerinden oluşur. Eğer isim soylu kelimenin son sesi ünlü ise "+nın, +nin, +nun, +nün”; yumuşak ünsüz ise “+dın, +din, +dun, +dün" ve sert ünsüz ise " +tın, +tin, +tun, +tün” gelir. Yazılı anlatım kâğıtlarındaki ilgi hâli ekleriyle ilgili yanlış örnekleri şu şekildedir: "Modern dünya yüzünden hastalıktın çeşitleri artıyor.", " $B u$ için tabiatı koruyalım, ağlatmayalım, kalbini kırmayalım." ve "Her dönemdin iyi tarafı var."

Yazılı anlatım kâğıtlarındaki soru ekiyle ilgili yanlıs örnekler şu șekildedir: "Biliyormusunuz, hayat gerçekten güzel.", "Sonucu nasıl olacak biliyormusunuz?" ve "Hayat çok kısa demi arkadaşlar?" Öğrencilerin soru ekini ayrı yazmamasının sebebi Kırgız Türkçesinde bitişik yazılmasıdır

Yazılı anlatım kâğıtlarındaki kip ve şahıs eki ekiyle ilgili yanlış örnekler şu şekildedir: "Dedem zamanında öğretmen olarak çalıştı (çalışmış).", "Tabiat da bizim gibi ağlayacak (ağlar), onun da kalbi kırılacak (kırılır).", "İnsan doğduğunda önce bebek olacak (olur) sonra çocuk, daha sonra gençlik ve en sonunda yaşlı olacak (olur).", "Ben çocukken "Ne zaman büyüyeceğim?" diye söyleyecektim (söylerdim).", "Kuşak çatışması, değişen değerler ve davranışlar sonucunda yaş farkı 5-10 ve üzerindeki bireyler için gerçekleşmeye başlayacaktır (başlar)."

Çalışmaya katılan öğrencilerin bu hataları yapmasının bir sebebi zaman eklerinin kullanımını karıştırmasıdır. Söz gelimi, geçmiş zamandaki olaylar bir başkasından öğreniliyorsa belirsiz geçmiş zaman; hiç değişmeyen durumlar, doğa olayları anlatıllyorsa geniş zaman; geçmişte sık sık yapılan, alışkanlık hâlinde olan, şu anda değişmiş olabilen durumlar anlatılıyorsa geniş zamanın hikâyesi kullanıılır. "Dedem zamanında öğretmen olarak çalıştı(çalışmış).", "İnsan doğduğunda önce bebek olacak (olur) sonra çocuk, daha sonra gençlik ve en sonunda yaşlı olacak (olur).", "Ben çocukken 'Ne zaman büyüyeceğim?' diye söyleyecektim (söylerdim)." cümlesi yanlış kullanıma örnektir.

\section{Sonuç ve Öneriler}

Bu çalışmada, Kırgız öğrencilerin Türkiye Türkçesi IV. ara sınavında yer alan yazılı anlatım sorularından herhangi birine verdikleri cevaplar ile hangi eklerde daha fazla zorlandıkları gözlemlenmiştir. Elde edilen veriler yardımıyla ek yanlışları gruplandırılmıştır Çalışmaya katılan öğrencilerin yazılı anlatımlarındaki ek kullanımına bakıldığında en fazla hata belirtme hâli ekinde yapılmıştı. Daha sonra sırası ile kip ve şahıs eki, fiilden isim yapım eki, ilgi hâli eki, soru eki, çıkma hâli eki ve yönelme hâli ekinde görülmüsstür. Çalışma verilerine bakıldığında öğrencilerin bulunma hâli ekinde herhangi bir zorluk yaşamadığ gözlenmiştir. Öğrenciler en az hatayı yönelme hâli ekinde, en çok hatayı ise belirtme hâli ekinde yapmış̧ır. Öğrencilerin bulunma hâli eki ve çokluk ekiyle ilgili hata yapmadıkları tespit edilmiştir. Şahin'in (2013) "Yabancı Dil Olarak Türkçe Öğrenen Öğrencilerin Yazılı Anlatımlarındaki Ek Yanlışları" adlı makalesi de bu araştırmanın verileri ile örtüşmektedir.

Çalışmaya katılan Kırgız yirmi sekiz öğrencinin ekleri kullanırken hata yapmasının bir sebebi olumsuz aktarım yapmasıdır. Buradaki hata öğrencinin ana diline göre düşünüp hedef dile aktarması sonucu oluşmuştur. Öğrencilerin olumsuz aktarım yapmasının önüne geçebilmek için yazma becerisine yönelik etkinlikler arttırılabilir. Öğretmen, Kırgız öğrencileri iyi analiz edebilir. 
Öğrencilerin ekleri kullanırken hata yapmasının bir başka sebebi dil içi hatalarıdır. Söz gelimi "Dedem zamanında öğretmen olarak çalıştı (çalışmış).” cümlesinin yazılmasının nedeni budur.

Yazma, yaşam boyu bireyin gereksinim duyduğu ve geliştirilmesi gereken bir dil becerisidir. Türkçe öğretiminde önemli bir yeri olan yazma becerisini öğrencilere kazandırabilmek ve öğrencilerin etkili bir yazı yazabilmelerini sağlamak için, uygulama çalışmalara ihmal edilmemelidir. Etkili bir yazılı anlatım öğretimi için öğrencilerin yazılı anlatım uygulamalarının mutlaka öğretmen tarafindan kontrol edilip öğrencilere dönüt verilmesi gerekmektedir. Bu tür bir değerlendirmede yazının, yazım ve noktalama kurallarına uygunluğu, sayfa düzeni, anlatımın akıcılığı, yaratıcılık, dili doğru ve güzel kullanma açıklık ve sadelik gibi noktalar göz önüne alınmalıdır (Yılmaz, 2015, s. 145).

Sonuç olarak, bu çalışmanın Kırgızlara Türkçe öğretiminde materyal, etkinlik ve yöntem belirleme açısından yardımcı olacağı düşünülmektedir.

\section{Kaynakça}

Bölükbaş, F. (2011). Arap Öğrencilerin Türkçe Yazılı Anlatım Becerilerinin Değerlendirilmesi. Turkish Studies, 6 (3), 1357-1367.

Çakır, İ. (2010). Yazma Becerisinin Kazanılması Yabancı Dil Öğretiminde Neden Zordur?. Sosyal Bilimler Enstitüsü Dergisi, (28), 165-176.

Çerçi, A., Derman, S. ve Bardakçı, M. (2016). Yabancı Dil Olarak Türkçe Öğrenen Öğrencilerin Yazılı Anlatımlarına Yönelik Yanlış Çözümlemesi. Gaziantep University Journal of Social Sciences, 15 (2), 695-715.

Çetinkaya, G. (2015). Yanlış Çözümlemesi: Yabancı Dil Olarak Türkçe Öğrenen B2 Düzeyindeki Öğrencilerin Yazılı Metinlerine İlişkin Görünümler. International Journal of Languages' Education and Teaching, 3 (1), 164-178.

Gümüş, M. (2014), Türkçe ile Kırgızca Dil Yapılarının Dil Öğretimi Amaçlı Karşılaştırması. Basılmamış Yüksek Lisans Tezi, Ankara Üniversitesi, Ankara.

Maden, S., Dinçel, Ö. ve Maden, A. (2015). Türkçeyi Yabancı Dil Olarak Öğrenenlerin Yazma Kaygıları. Uluslararası Türkçe Edebiyat Kültür Eğitim Dergisi, 4 (2), 748-769.

Özeren, M. (2016). Kırgız Türkçesi Ağızlarında Hâl Eklerinin Kullanımı. A. Ü. Türkiyat Araştırmaları Enstitüsü Dergisi [TAED], 56, 739-766.

Şahin, E. Y. (2013). Yabancı Dil Olarak Türkçe Öğrenen Öğrencilerin Yazılı Anlatımlarındaki Ek Yanlışları. Tarih Okulu Dergisi (TOD), (XV), 433-449.

Yıldırım, A. ve Şimşek, H. (2013). Sosyal Bilimlerde Nitel Araştırma Yöntemleri, (9. bs.) Ankara: Seçkin Yayıncılık.

Yılmaz, F. (2015). Tokat GOÜ TÖMER'de Türkçe Öğrenen Öğrencilerin Yazım Alanında Yaptıkları Hatalar. Route Educational and Social Science Journal, 2 (1), 130-147. 